\title{
PROPEDEUTIC COURSE FOR A MASTER ON TECHNOLOGY IN ARCHITECTURE
}

\author{
J.Roset ${ }^{a}$, G. Rojas ${ }^{b}$ \& A. Rybka ${ }^{c}$ \\ a Departament de Física Aplicada (ETSA Barcelona) \\ Universitat Politecnica Catalunya \\ jaime.roset@upc.edu \\ ${ }^{b}$ Department de Construccions Arquitectòniques I \\ Universitat Politecnica Catalunya \\ gilkauris.maria.rojas@estudiant.upc.edu \\ ${ }^{c}$ Faculty of Civil and Environmental Engineering and Architecture \\ Rzeszow University of Technology \\ akbyr@prz.edu.pl
}

\section{SUMMARY}

Masters dealing on Technology have an important problem in the usual case of students coming from very different countries. Due to the important dispersion on how to teach technological contents for architects, very different initial levels are found. Any decision you take as a teacher will provoke either bored students or stressed students. It is likely that both types of students appear to be frustrated.

The aim of this work is to propose a PROPEDEUTIC MASTER matter to be passed for "new in the topic" candidates to attain main core of the master studies. A minimum time of 5 ECTS is proposed corresponding to 50 hours in the classroom and 75 hours work by the student. Impartation is proposed 2 weeks before the starting of the "main core" matters. As the syllabus is referred to, five 10 hours lectures packages are proposed: Mathematics. Statics, Environmental Physics, Drawing, Philosophy of science.

Key words: Postgraduate studies, propedeutic, technology in architecture 


\section{INTRODUCTION}

Escola Tècnica Superior d'Arquitectura de Barcelona (ETSAB) has more than 1000 postgraduate students. Among them, about 300 per year are enrolled in Master courses and receiving lectures at the School. Approximately 80 students per year are taking matters related to Technology. (Figure 1)

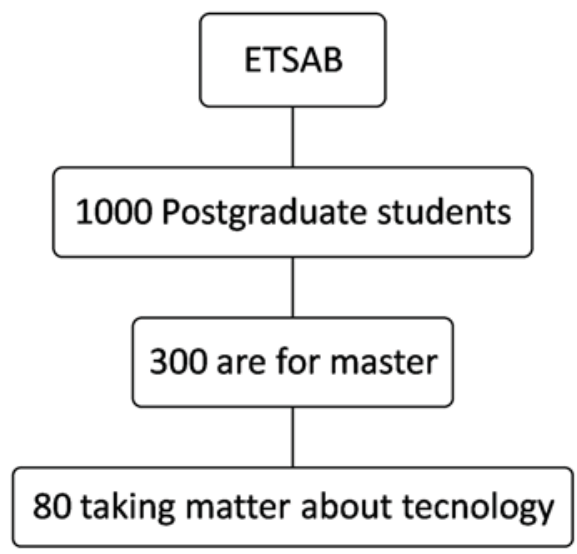

Figure 1. Students flow structure.

Architecture studies programmes are rather diverse in different countries of the world. Particularly, in Technology topics, architects entitled from Spanish systems are, usually, more skilled in Technology than students coming from other latitudes. (Figure 2)

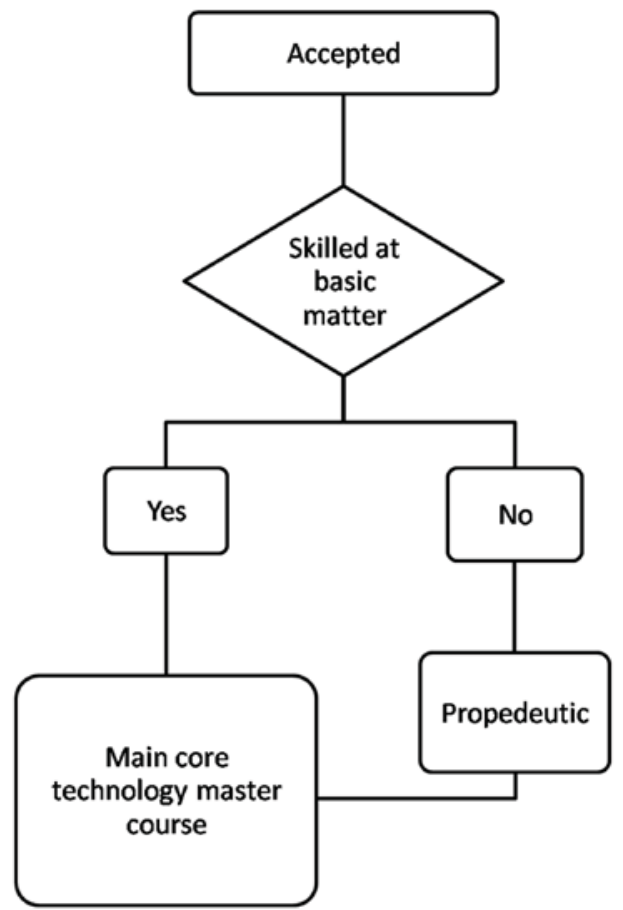

Figure 2. Escola Tècnica Superior d'Arquitectura de Barcelona. (ETSAB).

This better performance is, probably, due to the attributions that Spanish architects have doing jobs that, in other latitudes, and is done by Civil Engineers 
(Structural behaviour), Mechanical Engineers (Acclimatization) or Electrical Engineers (Electric Building Services). (Figure 2)

From this initial disparity, if teachers try to equalize them, they can provoke disinterest in some students and stressing of some others resulting in a loss of efficiency. Some countries are making an important effort for granting students but, logically, they are exigent in the good profit these students have to show. As a consequence of this initial lack, some students do not obtain good marks with the consequence of not having good opportunities for possible granting of further studies (like $\mathrm{PhD}$, for example). In the general frame of a new re-organisation of master studies at ETSAB, we will to contribute with a proposal for a new propedeutic matter.

Present paper is organised in sections. At the second section, we will expose a series or conditions for a good transmission of knowledge, skills and attitudes. Third section will deal with the contents of the matter taking into account characteristics of the students and capabilities of the teachers. Fourth section will propose to different possible scenarios for actual impartation of the matter. Fifth section will offer a kind of conclusion of our proposal.

\section{CONDITIONS FOR A GOOD TRANSMISSION}

Problem of the transmission of knowledge and skills from a discipline (like Physics) to an applied profession (like Architecture) has been studied by several authors (Roset and Serra Florensa 2006)(Roset 2006). Our results show that a good transmission should fulfill several conditions in order to be successful and to avoid other. Three conditions must be fulfilled: Completeness, Clearness, Disposal and Values. Moreover, two conditions must be avoided: Saturation of student's capability of understanding and "scientific lies" (i.e. explanations that could suggest bad results).

In a classical approach of knowledge, skills and attitudes of our students pretend they know what appears in the curriculum, they are capable of solving certain exercises and pass exams, finally they are always ready to learn more and more. Our experience has led us to focus not so much in what we want to convey but in the way to do this transmission. So, we will formulate policies to accomplish and others to avoid.

In order to accomplish:

- $\quad$ Completeness: Student must be informed at any moment (at the start and during the process) about all we want to explain. So, each lecture has to "make sense" for the student.

- $\quad$ Clarity: Teachers will do our best for preparing models where ALL the parts will be clearly explained. Searching clarity never has to imply renouncing to rigor

- "Numerical" values: At "near all" process phases, students must have an option for quick evaluating our "road"

In order to avoid:

Saturation: Students' saturation (it is proved that more than 40 or 50 minutes is a limit for good concentration). 
- $\quad$ Physical "lies": Unexplainable parts in the process or parts that will imply false implications. Do not use expressions like "it is clearly seen" or "it is easy to demonstrate".

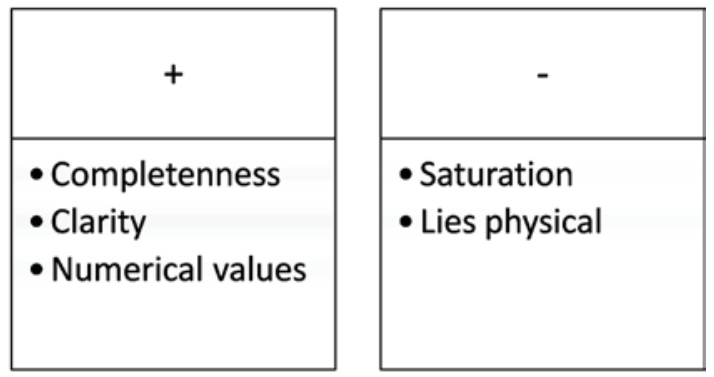

Figure 3. Conditions to accomplish and avoid for good transmission systems.

Next section will be devoted to define what we want to do. Who are the target students, what syllabus must be taught and how would be our teaching team.

\section{IDEA OF THE MATTER: STUDENTS, SYLLABUS AND TEACHERS}

Students' needs plus contents of the matter plus teachers' characteristics will define our matter.

Target students: Architects (or other admitted people) willing to study at the Technology related matters in ETSAB. Some of the admitted students would have been asked by Studies Commission of the master for following this propedeutic matter. This same Commission will establish criteria for succeeding in the matter.

- Diversity in the origin and previous training of the students (we talk about 10 different nationalities in a 20 students group) puts a challenge for designing a good syllabus that can be followed for all of them. So, our proposal will focus in the most basic topics (mathematics, drawing) while browsing necessary topics for a master in Technology (statics, environmental physics). All these topics need to be related by a more general matter (philosophy of the Science) in order to guarantee the completeness of our explanations.

- Detailed Syllabus: Mathematics. Statics, Environmental Physics, Drawing, Philosophy of science. (Figure 4)

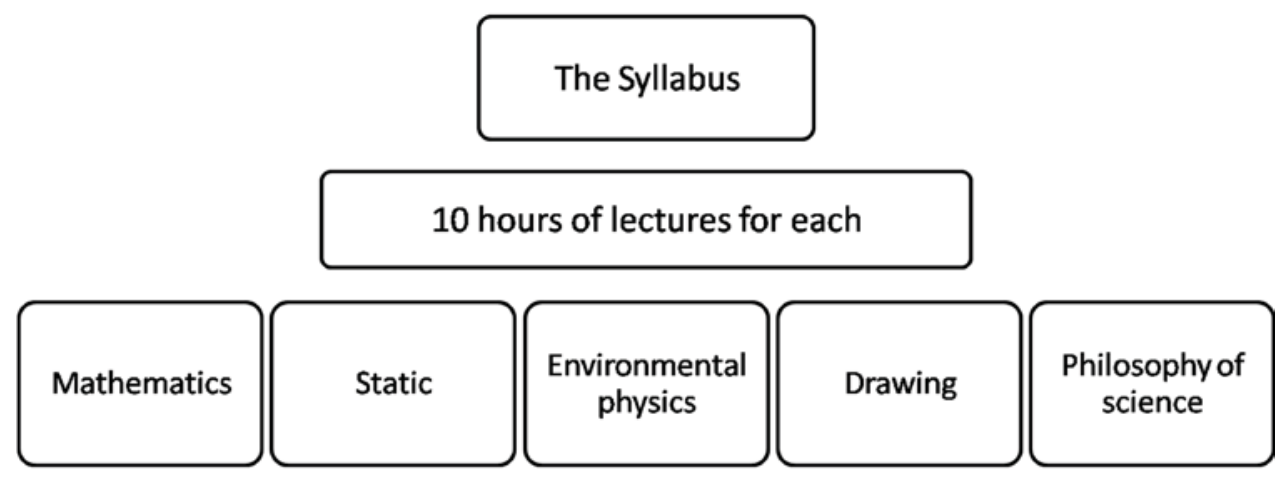

Figure 4. The Syllabus. 
- $\quad$ For each of these parts (sub-chapters), we have defined a Detailed Objective that could be evaluated at the end of the matter. (Table I)

\begin{tabular}{|c|c|}
\hline $\begin{array}{c}\text { Sub-chapter } \\
\text { (knowledge) }\end{array}$ & $\begin{array}{c}\text { Detailed Objective } \\
\text { (evaluable skills) }\end{array}$ \\
\hline Mathematics & Use of worksheets \\
\hline Statics & $\begin{array}{c}\text { Calculation of flexural moments, } \\
\text { shear forces, linear elasticity }\end{array}$ \\
\hline Environmental Physics & $\begin{array}{c}\text { Basis of thermodynamics, heat } \\
\text { transfer, acoustics and lighting }\end{array}$ \\
\hline Drawing & $\begin{array}{c}\text { Hand drawing and using of simple } \\
\text { tools (Sketch-up, Autocad, ...) }\end{array}$ \\
\hline Table I. Detailed objectives of our syllabus & $\begin{array}{c}\text { General context, skills in scientific } \\
\text { communication }\end{array}$ \\
\hline
\end{tabular}

It should be covered in 5 ECTS, corresponding to 50 hours of lectures and 75 hours of work by student. (Figure 5)

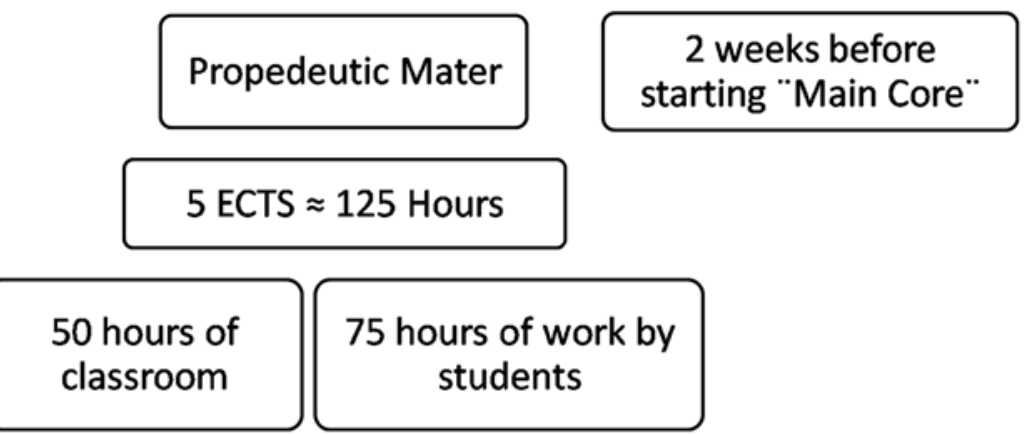

Figure 5. Propedeutic Matter.

- $\quad$ Teachers: Experienced teachers mainly working at propedeutic levels by our School. A balance between senior teachers and young teachers has to be maintained. ETSA of Barcelona has enough prepared teachers. These teachers should act in a very well-coordinated way because, in our opinion, the success of the matter strongly depends on their capability of transmitting a global idea of the topics treated. In fact, for us, relation teacher-student is the most crucial point for good results in teaching-learning.

\section{DEVELOPMENT OF THE MATTER: PROPOSED TIME SCENARIOS FOR IMPARTATION}

First and most desirable, in our opinion, scenario would be impartation of the matter in a "presential" manner during two weeks before the start of the Master for the generality of students. In that scenario we could appreciate, besides the acquisition of knowledge and skills by the students, their attitude for learning in the particular ambiance of our School.

For sure, this could result in an increase of costs for students (maintenance in Barcelona, for example), so a second scenario could be proposed. A semipresential scenario using Skype for some lectures and taking tasks by 
Internet, then we could split the matter about one semester but leaving some days for a face to face final presentation. (Figure 6)

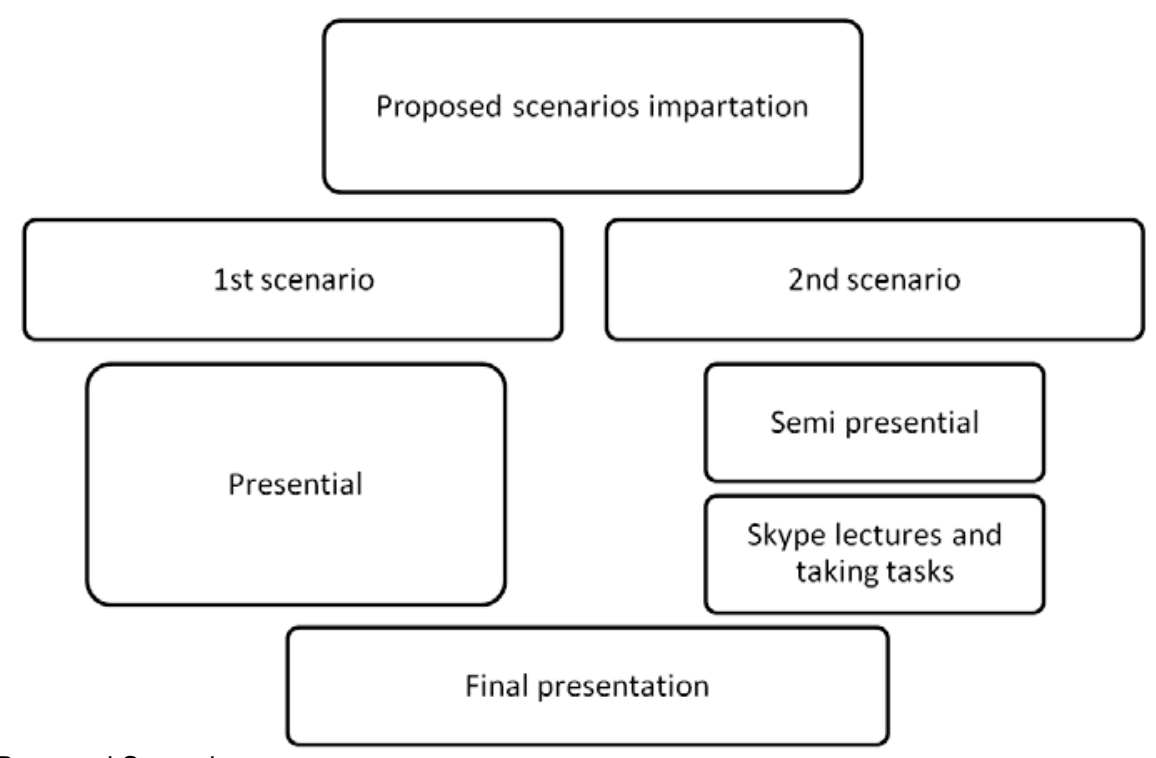

Figure 6. Proposed Scenarios.

We will enhance that first scenario is better in order to have our students in direct contact with our teachers. It would facilitate their quicker integration to the particular forms of working at our school.

\section{A KIND OF CONCLUSION}

Facing the problem of unbalanced initial level of students in Technology masters would be important for the success of an important amount of the master students by the ETS Arquitectura of Barcelona. We estimate this problem can affect about 40 students a year. We will remark that nations of some of these students are making an important economic effort for granting them. So, unsuccessful results of these students will mean an inefficient use of resources.

We have proposed a possible solution for the problem. Our proposal is prepare a propedeutic (introduction) matter for these students. We propose a 5 ECTS matter as a minimum requirement for a attaining our objectives.

Studying our target students and taking into account our teachers capabilities, we propose a syllabus including basic matters with detailed -evaluable- objectives for each sub-chapter.

A similar work - with students of only one nationality- has been still done in the Sustainable building master by Civil Engineering, Environmental Sciences and Architecture School by the Rzeszow University of Technology in Poland (Rybka et al. 2015). There, students coming from Architecture Department enter courses among students trained in Civil Engineering tools. We have taken into account this experience in order to make our proposal. For us, incorporation of this kind of propedeutic course in master studies could result in an important increase of their success.

We are convinced it will improve our teaching. 


\section{ACKNOWLEDGMENTS}

COST TU 1104 Action "Smart Energy Regions" has helped with a Short Term Scientific Mission by profesor Rybka in Barcelona (February 2014)

\section{BIBLIOGRAPHY}

ROSET, J. 2006. Física aplicada a l'ensenyament de l'arquitectura. ACE [en línea], vol. 1 , no. 1886-4805, pp. 2. Disponible en: http://upcommons.upc.edu/revistes/bitstream/2099/2079/1/TEM_roset_ARTICUL O.pdf.

ROSET, J. and SERRA FLORENSA, R. 2006. Física Aplicada a l'ensenyament de l'arquitectura. S.I.: Universidadt Politecnica de Cataluña.

RYBKA, A., KOZLOWSKA, K., SEP, M. and POMYKALA, A., 2015. Master's Program, Sustainable building (M. Sc.) at Rzeszow University of Technology. 2015. Cardiff: The Welsh School of Architecture, Cardiff University. (To be published) 